\title{
A Putative Role of Organic Anion Transporting Polypeptides (Oatps) In Cell Survival of Hormone-Dependent Breast and Prostate Cancers
}

\author{
Takeo Nakanishi* and Ikumi Tamai
}

Department of Membrane Transport and Biopharmaceutics, Kanazawa University, Japan.

${ }^{*}$ Corresponding author: Takeo Nakanishi, Department of Membrane Transport and Biopharmaceutics, Faculty of Pharmacy, Institute of Medical, Pharmaceutical and Health Sciences, Kanazawa University, Kakuma-machi, Kanazawa 920-1192, Japan; Tel: +81-76-234-4478/4421; Fax: +81-76-264-6284 E-mail: nakanish@p.kanazawa-u.ac.jp

Received Date: July 24, 2013 Accepted Date: August 06, 2013 Published Date: August 08, 2013

Citation: Takeo Nakanishi (2013) A Putative Role of Organic Anion Transporting Polypeptides (Oatps) In Cell Survival of Hormone-Dependent Breast and Prostate Cancers, J Cancer Res Therap Oncol 1: 1-6

\begin{abstract}
Transporter proteins classified into the solute carrier (SLC) transporter superfamily are essential for import of nutrients for cell survival in organisms. In the last two decades, compelling evidence has accumulated that SLC transporters interact with clinically important anticancer agents and contribute to their pharmacokinetics, particularly the biopharmaceutical processes of absorption, elimination and distribution. Furthermore, many SLC transporters have been shown to be differentially upregulated in cancer cells, and this may represent an adaptive response to altered nutritional requirements. Thus, it is likely to utilize them as carrier for efficient drug delivery as well as pharmacological target to shut off the essential nutrients for cell growth of malignant tumors. This short review will introduce organic anion transporting polypeptides which recognize endo- and exogenous organic anionic compounds and recent findings about their upregulation in cancer cells. Besides, OATP-mediated sulfate conjugates of steroid hormone may contribute to cell survival and adapted growth under hormonedepleted conditions. Better understandings of pathophysiological role of OATPs likely provide key information to overcome hormone-refractory breast and prostate tumors.
\end{abstract}

\section{Abbrevations}

ADT: Androgen Deprivation Therapy; CRPC: Castration Resistant Prostate Cancer; E3S: Estrone-3-Sulfate; DHEAS: Dehydroepiandrosterone Sulfate; FDG: 2-[fluorine-18]-Fluoro-2-Deoxy-D-Glucose; OATP: Organic Anion Transporting Polypeptide; PET: Positron Emission Tomography; mTOR: Mammalian Target of Rapamycin; SLC: Solute Carrier; STS: Steroid Sulfatase.

\section{Keywords}

SLC transporters; OATP; Hormone-refractory cancer; Chemotherapy; Breast; Prostate

\section{Introduction}

Membrane transporter proteins encoded by a number of gene families may play important role in cell survival because they are essential for import of key nutrients, which is hydrophilic and impermeable to plasma membranes by itself, including glucose and amino acids. It is collectively known that many influx transporters classified into solute carrier transporter (SLC) superfamily are upregulated in malignant tumors, although their physiological relevance has to be determined.

C2013 The Authors. Published by the JScholar under the terms of the Creative Commons Attribution License http://creativecommons.org/licenses/ by $/ 3.0 /$, which permits unrestricted use, provided the original author and source are credited.
For instances, enhanced expression of glucose transporter GLUT1/SLC2A1 in cancer cells is a molecular target for cell entry of the most common PET imaging agent in clinical use, FDG (2-[fluorine-18]-fluoro-2-deoxy-D-glucose), allowing to diagnose where malignant tumors are located $[1,2]$. Besides, several transporter proteins for amino acids such as leucine and glutamine have been well documented to be upregulated in many types of cancer cells, $[3,4]$ showing their critical role in nutrient signaling to mTOR and cell growth [5]. In addition to amino acid transporter, we have shown that enhanced activity of peptide transport in cancer cells [6,7]. Thus, differential upregulation of influx transporter could be utilized not only to efficiently deliver 
their substrate drug with anti-tumor activity [3,7] or diagnostic markers $[4,8,9]$, but also to shut off nutrient essential for cell growth; therefore, they can be promising target for a new chemotherapy. In this short review, we introduce our recent progresses regarding pathophysiological role of enhanced organic anion transporting polypeptides, OATPs, in cell proliferation of hormone-dependent breast and prostate cancers, implying pharmacological intervention of OATPs may contribute to efficient eradication of cancer cells.

\section{OATPs}

Organic Anion-Transporting Polypeptides (OATPs) are currently classified into the SLCO family consisting of 12 individual members, which have been basically characterized capable of transporting wide range of organic anionic compounds $[10,11]$. Human cDNAs of OATP1A2, 2B1, 1B1, 3A1 and $4 \mathrm{~A} 1$ were originally identified in our laboratory [12] and roles of OATP2B1, 1B1 and 1A2 among those in drug pharmacokinetics and disposition have been well established by many researchers $[11,12]$. Members of this family generally mediate $\mathrm{Na}+$-independent transport of amphipathic organic anion compounds and their substrates include bile salts, steroid conjugates, thyroid hormones and oligopeptides [11] as well as numerous drugs including major anticancer agents such as methotrexate[13], paclitaxel [14], SN-38 [15], and decetaxel [16]. Recent progresses about OATP family members in drug metabolism and disposition were reviewed in $[17,18]$ with summarized list of their substrates. Nowadays, it becomes convincing that expression of OATP molecules are enhanced in many types of cancer cells; however, there is no established rationale why they are over-expressed and how they contribute to cell growth in malignant tumors.

\section{Enhanced Expression in OATPs in Cancer Cells}

OATP1B3 is one the most studied OATPs in cancer cells, and has been documented its enhanced expression in gastric, colorectal, pancreatic and breast cancer, but not hepatocellular carcinomas $[13,19]$. Lee et al $[20]$ detected OATP1B3 protein expression in 75 out of 93 patient-derived colon adenocarcinomas $(81 \%)$ and no immunostaining in normal samples, and more interestingly OATP1B3 exhibited antiapoptotic effect, providing a survival advantage by altering $\mathrm{p} 53$-dependent pathways [20], although substances transported by OATP1B3 was not identified in relation to the effect in the research. They later found that colon cancer cells express truncated form of OATP1B3 with limited transport activity because of missing the first 28 amino acids [21]. Independently, similar observation was made in cancer-type isoform of OATP1B3 mRNA that is expressed in colon and lung cancer cells. Since it was described to lack 47 amino acids at $\mathrm{N}$-terminus, it may not be identical to the former one [22]. Thus, differences in expression and function may provide a clue to understand to clinical significance of OATP1B3 expression in cancer. Collectively OATP1B3 recognizes and transports major anticancer agents; therefore, such differential expression of OATP1B3 may determine their efficacy in chemotherapy, thereby resulting in providing a clinical benefit.
In addition to OATP1B3, other OATPs are also known to be highly expressed in cancer cells. A recent study with patientderived prostate tumor specimens indicates that mRNA expression of six SLCO genes, including SLCO1B3 and 2B1, was enhanced several-fold in castration resistant prostate cancer metastases, compared to untreated prostate cancer, implying their association with prostate cancer-specific motility [23]. Previous research suggests OATP1B3 is involved in transport of testosterone [24]. Overall survival of patients with prostate cancer in response to ADT therapy is affected by genetic variants of SLCO2B1 and SLCO1B3. Therefore, OATP may help prostate cancer cells to increase gonadal androgen availability [25]. Many groups including us have also implied possibility of overexpression of OATP2A1, OATP3A1, OATP4A1, OATP5A1, and OATP4C1 in breast cancer cell lines, including MCF-7 and T-47D cellsv [26-28]. OATP1A2 was shown to be upregulated in neoplastic breast tissues obtained from patients [29]. Furthermore, remarkable expression of OATP1A2 and 2B1 was reported in patient-derived human gliomas [30]. Considering the wide spectrum of substrate specificity of these transporters, these observations suggest that the transporters are one of determinants of efficacy of their substrate anti-cancer agents.

\section{Role of OATPs in Hormone Dependent Cancer Cells}

Breast cancer: It is known that steroid sulfatase (STS) activity is often detected in breast cancer cells at a considerably higher level than aromatase. STS catalyzes a hydrolysis of sulfate conjugates of steroid hormone to their unconjugated form; therefore, inactive estrone 3 sulfate (E3S) can be converted to estrone and then eventually used to generate biologically active estrogen by breast cancer cells, more likely, under estradioldepleted conditions such as post-menopausal women. Since OATPs efficiently facilitate cell entry of hydrophilic E3S, they may contribute to breast tumor progression in cooperation with STS. This hypothesis is tested by feeding hormone-responsive breast cancer cells with E3S to determine if E3S stimulates their growth. A significant increase in MCF-7 [26] and T-47D [27] cell growth was observed. Furthermore, we have recently shown that OATP1B3 is differentially upregulated in a sub-population of MCF-7 cells, suggesting that OATP1B3 serves as E3S transporter to allow breast cancer to survive under depletion of active estrogen such as estradiol [31]. This notion is also supported by enhanced STS expression correlated with increasing grade of breast tumors in 120 clinical specimens [32]. Increased expression of OATP1A2, which can transport E3S, mediated by PXR in breast tumor tissues fed with E3S supports this as well $[17,9]$. These observations suggest that OATPs at least in part contributes to tumor growth by regulating hormone dependency providing an adopted cell survival of breast cancer cells. Although it remains necessary to clarify the contributions of these OATPs to tumor growth, it is conceivable that developing a potent OATPs inhibitor with high affinity kills efficiently hormone refractory breast cancer that acquired by in treatment with aromatase inhibitors such as anastrozole and letroxole. 
A

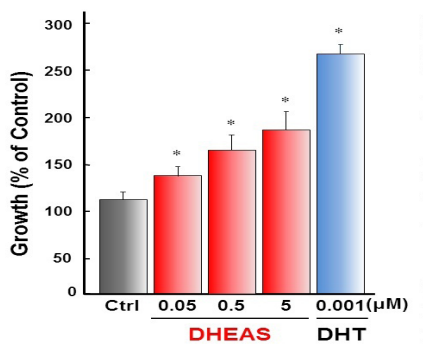

B

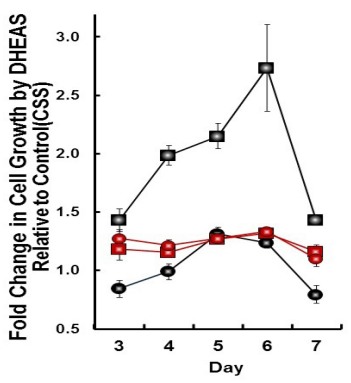

Figure 1: Hypothesized role of OATPs in cell survival in prostate cancer cells under gonadal androgen depletion condition

Testosterone plays a role in cell growth and proliferation of prostate cancer cells and crosses the plasma membranes by simple diffusion by itself. Testosterone is converted to dihydrotestosterone (DHT) by $5 \alpha$-reductase ( $5 \alpha \mathrm{R})$, and then binds to androgen receptor (AR). DHT-bound AR homodimerizes, enters nuclear and regulates gene expression so that it proceeds cell growth and releases PSA. Under the condition where testosterone is deprived of, cell entry of abundant plasma DHEAS may be facilitated by enhanced OATPs and DHEAS can be converted to DHEA, a weak androgen, by steroid sulfatase (STS), whose expression is not affected by availability of androgens. Since DHEA is converted to testosterone by multiple enzymatic reactions, handling of DHEAS by interplay of OATPs and STS may impart vulnerable prostate cancer cells an alternative source of androgens.

Prostate cancer: In human prostate cancer, gonadal androgens is critical for protein synthesis and cell survival [33]. Endocrine therapy that removes gonadal testosterone or antagonizes androgen receptors is currently a mainstream to treat prostate cancer. Although this Androgen Deprivation Therapy (ADT) is efficient, the disease may progress to the stage of CastrationResistant Prostate Cancer (CRPC). Once CRPC is developed, it no longer responds to ADT. Since CRPC tumor progression is still considered to associate with enhanced androgen receptor (AR) function [34-36], residual androgen availability, e.g. adrenocortical androgen, may be involved in the progression. In addition to E3S, OATPs can translocate dehydroepiandrosterone sulfate (DHEAS), $[11,37,38]$ which is a thousand fold more abundant than testosterone in human serum [39] and is basically unchanged by ADT. DHEAS is hydrolyzed to DHEA by STS [40] and then can further be converted to androstenedione, a weak androgen in prostate cancer [41], thereby resulting in stimulation of AR function (Figure 1), [42]. We have studied role of OATPs in an experimental CRPC cell culture model and recently reported OATP-mediated DHEAS is important for cell survival of prostate cancer [43]. Cell growth of ARpositive LNCaP cells was stimulated with DHEAS (Figure 2A) and the stimulation was abolished by an STS inhibitor, STX64. mRNA expression of various OATP genes were up regulated in LNCaP and 22Rv1 cells under androgen-depleted conditions [43]. Because OATP1A2 mRNA expression increased most prominently among those genes in LNCaP cells grown in androgen-depleted medium, LNCaP cells with OATP1A2 gene being silenced were established and designated KD16 and KD34. In both KD16 and 34 cells, the DHEAS-induced cell growth was not observed, compared to the control C3 and C9 cells (Figure 2B), [43]. Our results suggest that enhanced OATP1A2 expression is associated with adaptive cell growth of prostate cancer cells under androgen-depleted conditions. Thus, OATPs including OATP1A2 may play an essential role in rescuing prostate cancer cells from shortage of androgen such as testosterone by feeding DHEAS and utilizing it as a source of androgen in interplay of STS. This provides a new rationale to complement current endocrine therapy in combination use of an efficient inhibitor for OATPs if developed.

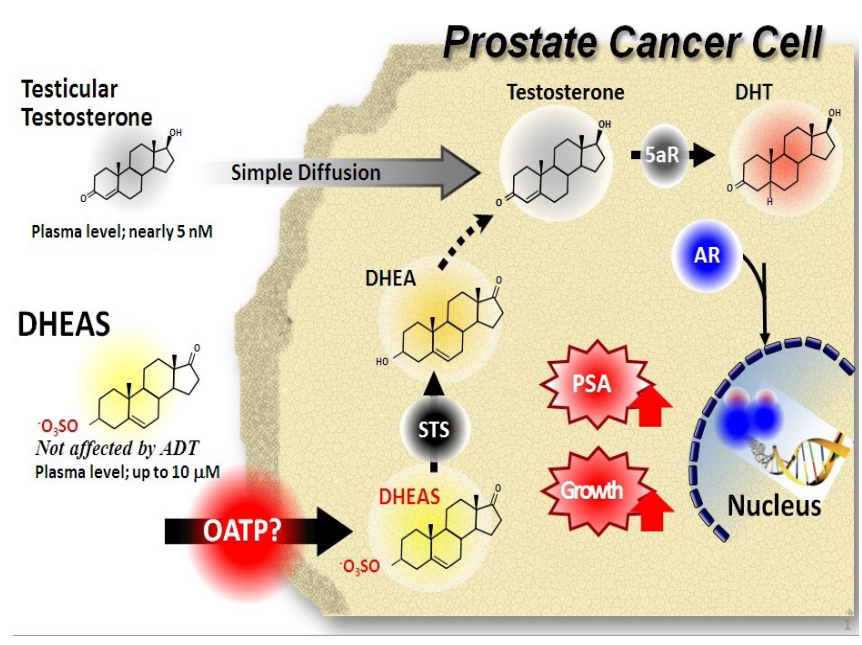

Figure 2: DHEAS-induced cell proliferation and impact of OATP1A2-mediated DHEAS transport on proliferation of LNCaP cells.

(A) Growth of LNCaP cells was monitored by means of SRB assay for up to 7 days. LNCaP cells cultured in RPMI1640 with $10 \%$ CSS for 7 days were seeded at 8,000 cells each in the presence or absence of androgen. Each bar represents the mean \pm S.E. $(n=6)$, and ${ }^{\star}$ indicates a significant difference from the control $(\mathrm{p}<0.05)$ by Student's t-test. (B) Stimulatory effect of DHEAS on growth of OATP1A2-knockdown (open) and control cells (closed) in sulforhodamine $\mathrm{B}$ assay. Cells were plated at 8,000 cells in each well. The ratio of cell growth to that without DHEAS $(5 \mu \mathrm{M})$ was calculated for control C3 (circle) and C9 (square), and OATP1A2-knocking-down KD16 (circle) and KD34 (square) each day. Each value is the mean of 7 or 8 individual results with S.E. $(n=4)$. These data was remade from originally reported by the authors (Ref.43).

\section{Conclusion}

There is compelling evidence that SLC transporters are upregulated in cancer cells on their demand. Among those, based on their nature, OATPs may be important players for regulating or adjusting hormone availability in hormone-dependent cancer cells. Although it is hard to exactly identify substances imported by OATPs to cancer cells, supplying sulfate conjugates of steroid hormone via OATPs allows breast and prostate cancer cells to use them as alternative source of active steroid hormones.

\section{References}

1) McGowan KM, Long SD, Pekala PH (1995) Glucose transporter gene expression: Regulation of transcription and mRNA stability. Pharmacology \& Therapeutics 66: 465-505.

2) Wahl RL (1996) Targeting glucose transporters for tumor imaging: "sweet" idea, "sour" result. J Nucl Med 37: 1038-1041.

3) Nakanishi T, Tamai I (2011) Solute carrier transporters as targets for drug delivery and pharmacological intervention for chemotherapy. J Pharm Sci 100: 3731-3750. 
4) Okudaira H, Shikano N, Nishii R, Miyagi T, Yoshimoto M, et al. (2011) Putative transport mechanism and intracellular fate of trans-1-amino-3-18Ffluorocyclobutanecarboxylic acid in human prostate cancer. J Nucl Med 52 : 822-829.

5) Fan X, Ross DD, Arakawa H, Ganapathy V, Tamai I, et al. (2010) Impact of system L amino acid transporter 1 (LAT1) on proliferation of human ovarian cancer cells: A possible target for combination therapy with anti-proliferative aminopeptidase inhibitors. Biochem Pharmacol $80: 811-818$.

6) Nakanishi T, Tamai I, Sai Y, Sasaki T, Tsuji A (1997) Carrier-mediated transport of oligopeptides in the human fibrosarcoma cell line HT1080. Cancer Res 57: 4118-4122.

7) Nakanishi T, Tamai I, Takaki A, Tsuji A (2000) Cancer cell-targeted drug delivery utilizing oligopeptide transport activity. Int J Cancer 88: 274-280.

8) Mitsuoka K, Miyoshi S, Kato Y, Murakami Y, Utsumi R, et al. (2008) Cancer detection using a PET tracer, 11C-glycylsarcosine, targeted to $\mathrm{H}+/$ peptide transporter. J Nucl Med 49: 615-622.

9) Okudaira H, Nakanishi T, Oka S, Kobayashi M, Tamagami H, et al. (2013) Kinetic analyses of trans-1-amino-3-[18F]fluorocyclobutanecarboxylic acid transport in Xenopus laevis oocytes expressing human ASCT2 and SNAT2. Nucl Med Biol 40: 670-675.

10) Hagenbuch B, Meier P (2004) Organic anion transporting polypeptides of the OATP/SLC21 family: phylogenetic classification as OATP/SLCO superfamily, new nomenclature and molecular/functional properties. Pflugers Arch 447: 653-665.

11) Nakanishi T, Tamai I (2012) Genetic polymorphisms of OATP transporters and their Impact on intestinal absorption and hepatic disposition of drugs. Drug Metab Pharmacokinet 27: 106-121.

12) Tamai I, Nezu J-i, Uchino H, Sai Y, Oku A, et al. (2000) Molecular identification and characterization of novel members of the human organic anion transporter (OATP) family. Biochem Biophys Res Commun 273: 251-260.

13) Abe T, Unno M, Onogawa T, Tokui T, Noriko Kondo T, et al. (2001) LST2 , a human liver-specific organic anion transporter, determines methotrexate sensitivity in gastrointestinal cancers. Gastroenterology 120: 1689-1699.

14) Smith NF, Acharya MR, Desai N, Figg W, Sparreboom A (2005) Identification of OATP1B3 as a high-affinity hepatocellular transporter of paclitaxel. Cancer Biol Ther 4: 815-818.

15) Yamaguchi H, Kobayashi M, Okada M, Takeuchi T, Unno M, et al. (2008) Rapid screening of antineoplastic candidates for the human organic anion transporter OATP1B3 substrates using fluorescent probes. Cancer Lett 260: 163-169.

16) Baker SD, Verweij J, Cusatis GA, Van Schaik RH, Marsh S, et al. (2008) Pharmacogenetic pathway analysis of docetaxel elimination. Clin Pharmacol Ther 85: 155-163.

17) Hagenbuch B, Meier PJ (2003) The superfamily of organic anion transporting polypeptides. Biochim Biophys Acta 1609: 1-18.

18) Hagenbuch B, Gui C (2008) Xenobiotic transporters of the human organic anion transporting polypeptides (OATP) family. Xenobiotica 38: 778-801.

19) Muto M, Onogawa T, Suzuki T, Ishida T, Rikiyama T, et al. (2007) Human liver-specific organic anion transporter-2 is a potent prognostic factor for human breast carcinoma. Cancer Sci 98: 1570-1576.

20) Lee W, Belkhiri A, Lockhart AC, Merchant N, Glaeser H, et al. (2008) Overexpression of OATP1B3 confers apoptotic resistance in colon cancer. Cancer Res 68: 10315-10323.

21) Thakkar N, Kim K, Jang ER, Han S, Kim D, et al. (2013) A cancer-specific variant of the SLCO1B3 gene encodes a novel human organic anion transporting polypeptide 1B3 (OATP1B3) localized mainly in the cytoplasm of colon and pancreatic cancer cells. Mol Pharm 10: 406-416.

22) Nagai M, Furihata T, Matsumoto S, Ishii S, Motohashi S, et al. (2012) Identification of a new organic anion transporting polypeptide 1B3 mRNA isoform primarily expressed in human cancerous tissues and cells. Biochem Biophys Res Commun 418: 818-823.
23) Wright JL, Kwon EM, Ostrander EA, Montgomery RB, Lin DW, et al. (2011) Expression of SLCO transport genes in castration-resistant prostate cancer and impact of genetic variation in SLCO1B3 and SLCO2B1 on prostate cancer outcomes. Cancer Epidemiol Biomarkers Prev 20: 619-627.

24) Hamada A, Sissung T, Price DK, Danesi R, Chau CH, et al. (2008) Effect of SLCO1B3 haplotype on testosterone transport and clinical outcome in caucasian patients with androgen-independent prostatic cancer. Clin Cancer Res 14: 3312-3318.

25) Yang M, Xie W, Mostaghel E, Nakabayashi M, Werner L, et al. (2011) SLCO2B1 and SLCO1B3 may determine time to progression for patients receiving androgen deprivation therapy for prostate cancer. J Clin Oncol 29: 2565-2573.

26) Nozawa T, Suzuki M, Takahashi K, Yabuuchi H, Maeda T, et al. (2004) Involvement of estrone-3-sulfate transporters in proliferation of hormonedependent breast cancer cells. J Pharmacol Exp Ther 311: 1032-1037.

27) Nozawa T, Suzuki M, Yabuuchi H, Irokawa M, Tsuji A, et al. (2005) Suppression of cell proliferation by inhibition of estrone-3-sulfate transporter in estrogen-dependent breast cancer cells. Pharm Res 22: 1634-1641.

28) Wlcek K, Svoboda M, Sellner F, Krupitza G, Jaeger W, et al. (2008) Altered expression of organic anion transporter polypeptide (OATP) genes in human breast carcinoma. Cancer Biol Ther 7: 1450-1455.

29) Meyer zu Schwabedissen HE, Tirona RG, Yip CS, Ho RH, Kim RB (2008) Interplay between the nuclear receptor pregnane $\mathrm{X}$ receptor and the uptake transporter organic anion transporter polypeptide $1 \mathrm{~A} 2$ selectively enhances estrogen effects in breast cancer. Cancer Res 68: 9338-9347.

30) Bronger H, Konig J, Kopplow K, Steiner H H, Ahmadi R, et al. (2005) $\mathrm{ABCC}$ drug efflux pumps and organic anion uptake transporters in human gliomas and the blood-tumor barrier. Cancer Res 65: 11419-11428.

31) Maeda T, Irokawa M, Arakawa H, Kuraoka E, Nozawa T, et al. (2010) Uptake transporter organic anion transporting polypeptide $1 \mathrm{~B} 3$ contributes to the growth of estrogen-dependent breast cancer. J Steroid Biochem Mol Biol 122: 180-185.

32) Al SW, Mokbel R, Salhab M, Jiang W, Reed M, et al. (2006) The role of STS and OATP-B mRNA expression in predicting the clinical outcome in human breast cancer. Anticancer Res 26: 4985-4990.

33) Brawer MK (2006) Hormonal therapy for prostate cancer. Rev Urol 8 : S35-S47.

34) LeCluyse EL, Madan A, Hamilton G, Carroll K, DeHaan R, et al. (2000) Expression and regulation of cytochrome $\mathrm{P} 450$ enzymes in primary cultures of human hepatocytes. J Biochem Mol Toxicol 14: 177-188.

35) Taplin M E, Bubley GJ, Shuster TD, Frantz ME, Spooner AE, et al. (1995) Mutation of the androgen-receptor gene in metastatic androgen-independent prostate cancer. N Eng J Med 332: 1393-1398.

36) Feldman BJ, Feldman D (2001) The development of androgen-independent prostate cancer. Nat Rev Cancer 1: 34-45.

37) Kullak-Ublick G A, Fisch T, Oswald M, Hagenbuch B, Meier PJ, et al. (1998) Dehydroepiandrosterone sulfate (DHEAS): identification of a carrier protein in human liver and brain. FEBS Lett 424: 173-176.

38) Cui Y, Konig J, Leier I, Buchholz U, Keppler D (2001) Hepatic uptake of bilirubin and its conjugates by the human organic anion transporter SLC21A6. J Biol Chem 276: 9626-9630.

39) Labrie F, Bélanger A, Cusan L, Gomez J L, Candas B (1997) Marked decline in serum concentrations of adrenal C19 sex steroid precursors and conjugated androgen metabolites during aging. J Clin Endocrinol Metab 82: 2396-2402.

40) Reed MJ, Purohit A, Woo LWL, Newman SP, Potter BVL (2005) Steroid sulfatase: Molecular biology, regulation, and inhibition. Endocr Rev 26: 171202.

41) Longcope C (1995) Metabolism of dehydroepiandrosterone. Ann N Y Acad Sci 774: 143-148. 
42) Evaul K, Li R, Papari-Zareei M, Auchus RJ, Sharifi N (2010) $3 \beta$-Hydroxysteroid dehydrogenase is a possible pharmacological target in the treatment of castration-resistant prostate cancer. Endocrinology 151: 35143520 .

43) Arakawa $H$, Nakanishi $T$, Yanagihara $C$, Nishimoto $T$, Wakayama $T$, et al. (2012) Enhanced expression of organic anion transporting polypeptides (OATPs) in androgen receptor-positive prostate cancer cells: Possible role of OATP1A2 in adaptive cell growth under androgen-depleted conditions. Biochem Pharmacol 84: 1070-1077. 